Authors' pre-publication copy - may contain typographical errors Full citation:

Henderson, H, Evans, A B, Allen-Collinson, J, Siriwardena, A N (2018) 'Wild and Woolly' world of Exercise Referral Schemes: Contested interpretations of an exercise as medicine programme, Qualitative Research in Sport, Exercise and Health, 10 (4): 505-523.

\title{
The 'wild and woolly' world of exercise referral schemes: contested interpretations of an exercise as medicine programme
}

Hannah E. Henderson (iD,Adam B. Evans (D), Jacquelyn Allen-Collinson (iD) Niroshan A. Siriwardena

https://www.tandfonline.com/doi/full/10.1080/2159676X.2017.1352018

https://doi.org/10.1080/2159676X.2017.1352018

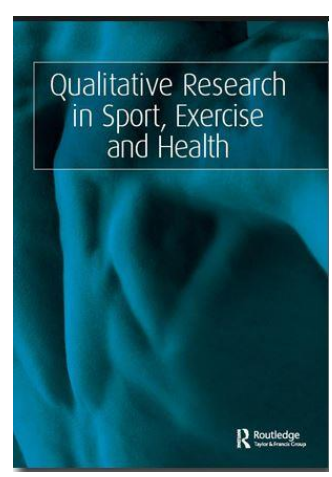




\title{
The 'Wild and Woolly' world of Exercise Referral Schemes: Contested interpretations of an
}

\section{exercise as medicine programme}

\begin{abstract}
Exercise Referral Schemes (ERS) are programmes commonly utilised in the United Kingdom to increase physical activity levels and 'treat' 'sedentary' individuals and those diagnosed with noncommunicable chronic disease. The views and interpretations of stakeholders are currently underresearched, however. This paper addresses sociologically this research lacuna, presenting data from interviews with 17 ERS stakeholders (7 exercise professionals, 5 Health Professionals and 5 strategic managers) in a case study English county. A figurational sociological lens was adopted to provide novel insights into the meanings attached to ERS, and their contestation through service-delivery models. Thematic analysis generated salient themes regarding divergent interpretations of ERS goals, and conflict within both service-delivery pathways and perceptions of programme impact. Our data highlighted conflicting and inconsistent stakeholder accounts within and across groups, suggesting participants attached specific, interdependent and sometimes contradictory meanings to ERS. This created conflict and generated interesting unintended consequences. Perceived divisions between strategic and local levels, and between professional groups emerged strongly. The consequences of such divisions are discussed, together with implications for future analyses of exercise as medicine programmes. In particular, results suggest that an excessive focus upon programme impact and enduser experiences may overlook the influence of stakeholder interpretation on how and why exercise is employed as medicine, by whom, for which individuals and in which circumstances.
\end{abstract}

Key Words: Figurations, exercise referral schemes, stakeholder interpretation, contestation, health, primary care 


\section{Introduction}

Physical activity (PA) and exercise, terms which are increasingly merged, have often been identified with good health, whilst physical inactivity is associated with increased risk for development of several prevalent non-communicable chronic diseases (Durstine et al., 2013; Lee et al., 2012; Malcolm, 2016; Organisation, 2013; Thorp et al., 2011). Consequently, PA promotion has become a primary strategy to increase population health (Malcolm, 2016). Nevertheless, the majority of adults and many children are insufficiently active to achieve health benefits (DoH, 2011; WHO, 2013). Despite efforts to define how best to deliver the PA 'message' to the inactive, effective, sustainable interventions remain elusive (Dugdill et al., 2005; Morgan, 2005, Kelly \& Barker 2016). Many exercise programmes have only short-term impacts, are beset by recurring errors (Kelly \& Barker, 2016) and a tendency towards 'lifestyle drift', described as the propensity for policy initiatives designed to tackle health inequalities to recognise complex social determinants, but then to drift 'downstream' towards individual, lifestyle-oriented solutions and investment in behavioural interventions (Carey et al., 2016; Popay et al., 2010). Despite this, the promotion of active lifestyles is ubiquitous in fields such as sport and exercise (e.g. Malcolm, 2016), education (e.g. CDC, 2011), community-level programmes (e.g. Evans et al., 2016; Fitzsimons et al., 2008) and in Primary Care (PC) (e.g. Hillsdon et al., 2002; Crone \& James, 2016).

In the United Kingdom (UK), PC organisations are amongst the strongest advocates of exercise for health (Hillsdon et al., 2002), in part because of their access to the (inactive) public (Graham et al., 2005). Approximately $95 \%$ of the UK population was estimated to access a general practitioner (GP) in 2007 (Hippisley-Cox et al., 2007). Primary healthcare professionals (PHCPs) are often considered powerful sources of health advice (Graham et al., 2005), and policy-makers have recognised the significant potential for the promotion of PA in this setting (NICE, 2013, 2014). Conversely, some question whether PHCPs have sufficient time, training, experience, confidence or legal support to 
take up such a role (Bull \& Bauman, 2011; Ward, 2014; Weiler et al., 2013), challenging PHCPs' prominent role in exercise and PA promotion (Ward, 2014).

In response to these concerns, Exercise Referral Schemes (ERS) have become increasingly popular since the early 1990s (Crone \& James, 2016; Dugdill et al., 2005), and are intended to give PC or allied health professionals the opportunity to refer patients to qualified exercise professionals for a structured, typically community based, programme of exercise (Kahn et al., 2002; NHS, 2001). The intention is for exercise professionals, using PC health and screening information (Dugdill et al., 2005), to devise a tailored programme of activity while closely monitoring clients over a period between 10 and 16 weeks (BHF, 2010; Williams et al., 2007) for treatment of existing conditions and prevention of further illness. Today, ERS are among the commonest health promotion and prevention interventions in PC, with around 600 UK schemes in 2006, offered by $89 \%$ of PC organisations (BHF, 2010; Scotland, 2006; Sowden \& Raine, 2008).

Nevertheless, delivery models and standards within ERS are highly heterogeneous, in part due to the relatively unregulated early development of ERS (Beck et al., 2016; Oliver et al., 2016). Rapid initial expansion saw many programmes delivered in an 'off-the-shelf' fashion, often uncritically copying preceding programmes, and lacking quality assurance, clearly defined goals, and robust evaluation (Crone \& James, 2016; Dugdill et al., 2005; Hillsdon, 1998; Oliver et al., 2016). Outcome measures in ERS evaluation studies are often very different, preventing comparison or demonstration of effectiveness (NICE, 2006; 2014; Pavey et al., 2011). These evaluations tend to assess ERS impact on quantitative health outcome measures or predictors of adherence and attrition (Gidlow et al., 2008; Harrison et al., 2005), PA behaviour change (Morgan, 2005; Williams et al., 2007) and programme efficiency (Williams et al., 2007). Qualitative analyses have focussed upon participant experiences (e.g. Moore et al., 2013; Hardcastle \& Taylor, 2001; Wormald \& Ingle, 2004), but often fail to account for heterogeneity in ERS as a '...complex multi-stranded PA programme' (Dugdill et al., 2005: 1395) 
with multiple stakeholders operating across several levels of delivery (Crone \& James, 2016; Oliver et al., 2016). Evaluations of programme outcomes often overlook the complexity in wider interpretations of programme 'efficacy', development and delivery (Mutrie \& Woods, 2003). Similarly, regulatory attempts rarely pay reference to the range of service capacity and resources in ERS (Dugdill et al., 2005; Sowden \& Raine, 2008). As Pawson (2013) outlines, outcome evaluations and randomised control trial study designs rarely pay due attention to provider interpretation and the complexity of context (Pawson, 2013). Indeed, the perspectives of PCHPs (Graham et al., 2005) and exercise professionals have seen limited attention (Moore et al., 2013), despite recognition of the centrality of their role within ERS provision (Moore et al., 2013; Gidlow et al., 2008; Morgan et al., 2016; Wormald \& Ingle, 2004), and evidence of resistance to attempts to regulate ERS (Ward, 2014). Even less attention has been paid to how these service providers' interpretations of ERS are coproduced according to their interactions, and how this influences service delivery and impact; all of sociological interest.

Here, we contribute new understandings of the complex domain of ERS based on qualitative research into a case-study ERS programme in the east of England, which investigated the ways in which strategic programme managers, healthcare professionals and exercise professionals variously defined ERS, its aims and outcomes, and how they perceived their role within, and ability to influence, ERS delivery. We explored similarities and differences in how these professional groups described the delivery structure of ERS, together with how they defined their own competencies, responsibilities, and chains of accountability. The research also investigated whether these professional groups produced, reproduced or reinterpreted existing guidance about exercise as medicine in their own practice, both within their own roles, and also in relation to other groups within ERS. The findings challenge some key taken-for-granted assumptions surrounding constructing and delivering exercise 
as medicine. To explore sociologically these complex group dynamics, a figurational sociological theoretical framework was adopted.

\section{The Figurational Framework.}

Figurational, or process sociology, is highly pertinent to understanding how the actions of all individuals within service delivery networks can influence programme delivery. Taking the work of Norbert Elias as a starting point, figurational sociology pursues a radical approach to understanding the nexus between individual and society, agents and structures, and object and subject, so that individual 'I' identities are theorised as situated within networks of 'we' and 'they' relationships, or figurations (Elias \& Schröter, 1991). Within figurations, relations, tensions and conflicts between two or more connected entities at all levels of integration in society can be described according to dynamic tension balances inherent in a 'triad of controls'; that is, between extra-human, inter-human and intrahuman relationships that are continuously in flux (Goudsblom, 1977; Wouters, 2014). These controls are constituted by several 'balances' that describe relationships in terms of control, power, dependency, information and orientation. Balances include those between competition and cooperation, external social controls and internal self-controls (or the balance between fremdzwänge and selbstwänge), power-balance, formalisation and informalisation, lust and intimacy, the We-I balance and involvement and detachment (Wouters, 2014).

Hence, rather than theorising social structures, figurational webs of relationships are constituted by the people situated within them. They are connected via reciprocal relationships, or 'interdependency chains', within which the short-term actions of individuals interweave to create long-term unintended consequences that are beyond the control of any individual or group (Elias \& Schröter, 1991; Jarvie \& Maguire, 1994). Furthermore, within figurations, relationships, or 'bonds of association' exist in interdependency chains that are dynamic, contested and subject to complex tension balances which are in flux, and can be simultaneously enabling and constraining (Elias \& Schröter, 1991; Jarvie \& 
Maguire, 1994). Bonds of association can also be more or less dense, expand or constrict according to their relative intensity and duration (Elias \& Scotson, 1994). Moreover, interdependency chains have an historical or temporal aspect, and long-term processes such as rationalisation, industrialisation, the monopolisation of violence and taxation within states and technological advances have led to a lengthening of interdependency chains (Elias, 1982; Maguire, 2005). For example, the expansion of communication systems and the internet means that many bonds of association are no longer just embodied, but also include virtual aspects (Evans et al., 2016; Maguire, 2005).

Of direct relevance to the domain of ERS, the above processes can influence the development of 'established' or 'outsider' groups within figurations (Elias \& Scotson, 1994). Established groups have a greater influence in defining the accepted socio-cultural norms of a figuration, and both established and outsider groups tend to define one another in interdependent terms. Elias and Scotson (1994) describe how established groups often create and reinforce collective myths by defining outsiders as law-breakers and status violators, characterise them in terms of the 'minority of the worst' (or occasionally by the minority of the best) or consider them in some way 'unclean.' Similarly, whilst resistance is possible, outsider groups sometimes uncritically accept these characterisations (Elias and Scotson, 1994). Hence, such inter- and intra-group relationships can influence gendered (Mansfield, 2007), class-based (Lake, 2013), ageist (Evans \& Crust, 2015; Evans \& Sleap, 2012) and embodied (Evans et al., 2016) behaviours in exercise and health.

Furthermore, understanding an individuals' position within a figuration, together with their perceptions of their ability to influence their social position, enables analysis of how individual actions can have an impact upon the rest of a figuration (Baur \& Ernst, 2011). At the same time, the full extent of the interdependency chains within which people exist are often beyond their awareness (Dunning, 1999). Here, again, it is important to emphasise that figurations do not exist independently 
of those who constitute them, and thus changes in extent, duration and characteristics of interdependency chains are also subject to limits according to the actions of individual bodies (Elias \& Schröter, 1991). Hence, the body forms a spatial and temporal fulcrum around which social processes act (Evans et al., 2016; Evans \& Crust, 2015). The embodied intersection of sociogenetic and psychogenetic processes has physiological, psychological, social and historical components which intersect at 'the hinge', which in turn drives the habitus (Elias, 1982; Elias \& Dunning, 1986).

Within figurational sociology, the habitus represents the juncture between conscious, socially regulated actions and unconscious decision-making in a way that influences behaviour, but does not determine it. Hence, individuals internalise the norms and behaviours considered socially acceptable, or remain above the 'threshold of repugnance' (Elias \& Dunning, 1986), for example, individual responsibility for the maintenance of healthy, active lifestyles (Elias \& Dunning, 1986; Shilling, 2003). Hence, long-term processes of problematization and the rationalisation of health serve to valorise regulatory, 'civilizing' practices and policies that cohere with the uncritical promotion of exercise as a social and personal 'good.' The way in which this promotion occurs, however, is far from uniform; civilizing processes in modern societies tend towards the increasing differentiation of tasks, together with decreasing contrast (and increasing varieties) in the types of actions that are seen to be acceptable (Elias \& Dunning, 1986). Hence, exercise and PA promotion by a range of social actors with increasingly specific competencies and roles is increasingly commonplace, whilst the way in which they seek to achieve their goals remains varied. This can have considerable implications for those 'prescribed' exercise as medicine and for those involved in exercise delivery. We now outline the context of the study.

\section{Exercise Referral Structure in the Case-study ERS}

The research took place in a rural county in the East Midlands region of England. ERS developed here from 2000 onwards in 7 districts, each offering its own version of the programme. Initially 
funded by small localised investment, from 2006 the county NHS formally commissioned ERS. Between 2006 and 2011, investment steadily increased, and the county's sports partnership (CSP) took up a strategic role within ERS alongside the newly formed 'Public Health' organisation, who were based in a local authority and replaced the NHS as strategic managers of ERS. Figure 1 demonstrates the organisation structure of ERS in the case-study county.

\section{Insert Figure 1 here.}

Within each ERS, healthcare professionals (typically General Practitioners and Practice Nurses, but also including physiotherapists and NHS weight loss advisors) referred patients directly to exercise professionals. Referrals were made for a variety of reasons, including (but not limited to) risk of cardiovascular disease, musculoskeletal disorders, psychological problems, metabolic illness, respiratory illness, neurological conditions and obesity. Exercise professionals then worked with referred 'patients' to deliver a 12-week exercise programme. All employees were included in quarterly fora organised by local Public Health and the CSP, which also served an evaluative function.Exercise activities on offer included gym sessions, swimming, led walks, gentle group exercise classes and badminton, through a range of community facilities, private gyms and schools. Largely ERS programmes were free of charge, and subsidised gym memberships were also offered following the programme.

\section{Study Methods}

Figurational studies can typically be situated within levels of theoretical abstraction (Baur \& Ernst, 2011), and the present research operated at the middle-range level; that is, a level of abstraction focused upon the configuration of bonds of association within the case study ER figuration, how individuals perceived their own position within and their ability to influence this configuration, and how norms and values relating to ER were produced, reproduced and resisted. 
The figurational approach also advocates a balance between involvement and detachment as part of an ongoing reflexive process. In an attempt to reconstruct her positionality in relation to the object of research, the principal researcher sought to make explicit her positionality to the subject of research as insiders to the research field (their verstehen), their subjectivity as a prerequisite for grasping meaning (perspektivität), whilst simultaneously being aware of (and discussing) her parteilichkeit, or partiality that could 'distort' research and analysis (Baur \& Ernst, 2011; Elias et al., 1987). The principal researcher had attended quarterly fora organised by Public Health and the CSP for several years, gaining experience of ongoing discussions in the case-study ER figuration. Other members of the research team were outsiders to this figuration. Therefore, as part of the process of making explicit her own positionality, the principal researcher utilised the minutes of these meetings as elicitation tools to reflect on what she felt she knew about the structure of the ER figuration, its operation, and her feelings during these meetings, particularly during times of high tension or significant change. These automethodological analytic reflections as 'headnotes' (Author 3, 2005) were discussed amongst the research team in an attempt to delineate elements which related to her verstehen and perskeptivität, but also highlighting and critically discussing elements of the researcher's parteilichkeit, such as political sympathies with a particular group or policy. These sensitizing procedures were then taken forward into data collection and analysis and continually reflected upon through ongoing discussions within the team.

Ethical approval for the study was obtained from the NHS in the UK. Participant recruitment followed several incremental phases. Initially, a purposive sample of seven exercise professionals (responsible for exercise supervision) was recruited, comprising five men and two women, three of whom were also ERS co-ordinators. Purposive sampling was deemed appropriate due to the need to gain data from a small population of key individuals at service-delivery level (Bryman \& Teevan, 2004). Snowball sampling was then used to recruit five PCHPs who had worked with the exercise 
professionals, and were responsible for referring patients into the programme. This latter group included one GP, two practice nurses, one physiotherapist and one NHS-based Weight Loss Advisor. This second phase of recruitment was highly challenging, and many PCHPs declined to participate, mainly citing high workload as a reason. Subsequently, additional participants were selected from staff located within the 'strategic management' level at district and county levels. Individuals recruited held decision-making roles within the same ERS and represented Public Health (two participants), the CSP (two participants) and one district manager, who was responsible for the same district as that from which Exercise Professionals were recruited. Table 1 provides participant pseudonyms and roles.

\section{Table 1 here.}

Individual, semi-structured interviews were utilised. In the case of exercise professionals and strategic managers, interviews were conducted face to face at a time and place convenient to participants, often at personal offices. Interviews lasted around 30 minutes for exercise professionals, and around 60 minutes for strategic managers. The same procedure proved impractical with PCHPs, however, who were unable to provide time and space for face-to-face interviews, so telephone interviews were employed. The lack of co-presence and co-visibility of interviewer and interviewee makes cuereading challenging, but these telephone interviews enabled engagement with participants who would otherwise be unavailable (see Smith \& Sparkes, 2016). Interviews with PCHPs lasted around 15 minutes. Interviews were designed to enable exploration of participants' opinions and experiences of ER from their own perspective, together with their perceptions of ERS goals and procedures.

Data were then thematically analysed (Clarke \& Braun, 2014) via a six-phase process of: Data familiarisation, coding, searching for themes, reviewing themes through a dialectical approach to theory and data, defining and naming themes, and writing up (Clarke \& Braun, 2014). Repeated close reading of the transcripts allowed general understanding of both the scope and context of the 
experiences to be gained (Bradley et al., 2007). This also enabled the researcher to become immersed in and familiar with the data (Sparkes \& Smith, 2013). Segments of text were identified as containing meaningful units, and a code was created and assigned to that particular segment (Thomas, 2006). Hence, data analysis encompassed, 'two-way traffic' between the adopted theoretical concepts, ideas, theories or models and observations and perceptions at the semantic level (Clarke \& Braun, 2014; Elias et al., 1987: 20). The intention was to seek 'reality congruence' by trying to ensure data reflected participants' 'reality,' rather than objective 'truths' (Dunning, 1999). We now turn to consider the salient findings.

\section{Results \& Discussion}

Key identified themes related to ERS delivery pathway structure and how individuals perceived their position in relation to others (both 'We' and 'They' groups). These themes relate to the goals of ERS, perceptions of ER management, dynamic and contested power hierarchies amongst ERS service providers, and perceptions of the sustainability of ER. These factors strongly shaped how ERS was delivered 'on the ground' and in turn revealed contested meanings regarding 'exercise as medicine'.

\section{Perceived exercise referral goals}

Participants from all levels of service planning and delivery outlined what they considered the key aims and objectives of ERS. It quickly became clear that multiple, often conflicting ideas existed, suggesting that the purpose of ERS lacked clarity for many. Numerous references were made to general health objectives at the population level which could be achieved via the reduction of health 'problems' on an individual basis, particularly obesity. References to vague notions of the benefits of being 'active' were also common. At all levels within the ERS delivery pathways, specific goals or target activities were largely absent. Paul (Public Health) for example, considered that ERS should: 
... enable individuals to be more physically active. To enable them to experience PA that gives health benefits to alleviate their problems... or just raise their quality of life.

Similarly, Susan (Public Health) appeared confused about the precise purpose of ERS, mentioning tackling the 'obesity agenda' but not specifically as a weight-loss programme:

I think it says... exercise referral isn't a weight loss programme. I think when it began it probably was more of that... I think it's quite tied, it's obviously quite tied to that obesity agenda.

This lack of clarity regarding aims and purpose was also apparent in interviews conducted with members of the CSP, the district lead, and at the level of service delivery. Again, both exercise and PCHPs referred only generally to 'health' at the level of 'the population' and most held an overall belief that ERS provided an essential means of tackling 'poor health'. One Exercise Professional, David, commented:

...well I do think it is an essential part of the modern day, we've got to this point you know, the way the country has gone with diet, with inactivity, with stigmas about places like gyms and things...[it's] an essential part of modern life and a service that was needed due to the poor health of the population.

Exercise professionals generally emphasized how ERS was a good idea, worthwhile and 'positive', and several long-serving members reflected upon having 'seen' positive impacts. Again, though, the specifics were largely absent in relation to target groups, goals and forms of activity. Here was 'lifestyle drift' writ large (Carey et al., 2016; Popay et al., 2010), and although many participants were familiar with discourses relating to ill health at the population level, most situated ERS at the level of individual behaviour change. This was particularly common amongst both Exercise 
Professionals and PCHPs, who highlighted the importance of supervision, and referred to the need for 'safety' and 'security' amongst 'patients'. For example, Natasha (ERS Co-ordinator) identified:

...it provides... a safer environment for them to be able to start exercising with the reassurance that there is an instructor there who might have or should have some knowledge of that particular condition and be able to give them a programme accordingly... so I think that it can be very beneficial.

References to participants' need for a safe and supportive environment were, however, largely absent from the accounts of strategic personnel, although common in many other accounts of exercise participation amongst groups perceived to be ill, frail or weak (e.g. Evans \& Crust, 2015; Tulle, 2012; Wheatley, 2005b). Such 'risky' bodies can often become marginalised from mainstream spaces of exercise and health, and researchers have noted how these views can normalise provision of separate spaces for, and constant supervision of exercise by established groups of professional 'experts' (e.g. Evans \& Crust, 2015; Wheatley, 2005a). In our research, many service providers reproduced constructions of 'patients' physical and mental frailty, in part due to their medical diagnosis, but also in terms of previously sedentary lifestyles. The link between inactivity and illness was rationalised, rarely challenged, and consequently it was frequently assumed that patients would find the spaces of exercise (such as gyms) intimidating. Their re-labelling as ERS spaces, coupled with the careful supervision by established groups of professionals, was construed as necessary to help patients become active. Notably, in accounts of ERS goals, little reference was paid to helping patients to adapt and sustain positive lifestyle change following completion or attrition from ERS, beyond vague notions of 'nursing' them back to health. Care in ERS, it seems, was paternalistic in conception.

Furthermore, several participants described how the goals of ERS had changed since attempts to centralise strategic decision-making across the county via the Public Health organisation in 2006. This formalization process resulted in a shift in management approach, which sought to forge co- 
operative bonds of association across the county. Through increasing involvement in delivery processes and strategic distribution of funding, strategic management could exert a degree of control through quality assurance and accountability. All those interviewed were in agreement regarding how ERS management structure and approach had changed; for example, Paul (Public Health) noted such performance management:

...we got into a project management performance, management routine... so it's become less laissez faire... the goal is to be more typically structured than unstructured.

Paul also acknowledged that the shift to a performance management approach was in stark contrast to how ERS had originally developed (at district level from the 'ground-up'). Nevertheless, such attempts at policy centralisation have been common in UK sport more widely (e.g.g Grix \& Phillpots, 2011). Janet (district lead) described this increasing prescriptiveness:

Yes, I'd say it has, probably because I have been involved for quite a long time. Initially the relationship was with the NHS [where Public Health previously resided] it was a much more fluid relationship so less prescriptive... As time has gone on and [Public Health] moved into local authority control, things have become more prescriptive.

CSP participants explained that taking this approach had been necessary to try to provide a standardised, countywide ERS. Despite these attempts, however, resistance to change was apparent at several levels of ERS provision, as Sam (CSP) noted:

I think the methods have probably changed, or it should have changed (laughs) I think in some places it would just be the same old school mechanism and I, unless you know, you won't stop that.

This resistance and its impact proved sociologically revealing.

\section{The 'wild and woolly' world of ERS: Conflict and contestation within ERS Delivery}


During interviews, perhaps due to participants' differing and rather vague descriptions of how exercise should be utilised as medicine in ERS, it quickly became apparent that service provision and the strategic management of ERS in the case study were contested. Here, 'treatment' was delivered through a complex figuration comprised of sentient 'I,' 'We' and 'They' groups, situated in tensile, relational power balances which were subject to shifting balances between external and internal controls, co-operation and conflict, I-We and they relationships and power-balances. These balances influenced participants' ability to define or influence what both the 'exercise' and the 'medicine' would look like over time and in space. This had a significant impact upon how ERS was delivered. Individuals' perceptions of role and perceived influence within the ERS figuration depended upon their situation within the ERS delivery pathway. Thus, strategic managers (Public Health and the CSP) tended to define their role at the county level, whilst District Managers tended to associate themselves with Exercise Professionals at the district level. The CSP members, however, were considered outsiders by many participants from other groups. PCHPs remained peripheral to all other groups, in a somewhat liminal space between general healthcare and the ERS figuration.

Participants from both Public Health and the CSP primarily considered themselves network facilitators and partnership builders at the county level, and cited their creation of county network group fora as evidence. These meetings were open to all service providers, and managers felt they facilitated the sharing of best practice. These feelings were not reciprocated at district level, however, and numerous references were made to a lack of clarity about roles and responsibilities at the strategic level, particularly the role of the CSP, as Janet highlighted:

[it's] difficult to say because I am not sure what [the sports partnership] brings [to the scheme] - I understand they are commissioned to provide coordination... obviously they coordinate meetings which takes time, and the outcomes from the meetings, but it doesn't have to be that organisation that does it as anyone could perform the function in my opinion 
These sentiments were echoed by Susan (Public Health), who considered the involvement of the CSP had created unnecessary bureaucracy, making goal-setting procedures unclear:

...how it is now I see it as perhaps an unnecessary layer... and I think there's a little bit of erm... sort of two lines of accountability perhaps or... you know two generals sort of running the army

Amongst strategic staff, therefore, the CSP were considered 'outsiders,' and the principal researcher reflected upon her observations of this at network meetings. Here, CSP staff contributed very little to meeting content or discussion beyond summarising and introducing the agenda. As the issue of ERS decommissioning became a higher priority (see below), the researcher also recalled a number of 'awkward silences' which seemed to highlight the peripheral role of the CSP. Indeed, Christine (CSP) admitted that the CSP had 'no power' in ERS because they neither funded nor delivered the programme, and had been part of the strategic management of the programme for the shortest time of any stakeholder groups. As Elias and Scotson (1994) noted, established groups tend to have bonds of association which are stronger, in part due to a longer duration within a particular figuration which build cohesion and facilitate the operation of the established group's positions of power (Lake, 2011). Despite the CSP's strategic position in ERS management, it appeared that other 'we' groups within the existing delivery pathway of the ERS still viewed them as recent interlopers, to whom they were not directly accountable.

The sharing of best practice was also a contentious issue, and the selective completion of 'feedback' by district level staff appeared to be a form of resistance to guidance and control from all strategic stakeholders. Whilst all participants discussed how important feedback about service quality was, the level of feedback provided depended upon the level of face-to-face interaction that staff had with one another. As in other cases examining how programmes are co-interpreted between individuals (or IWe-They configurations of bodies) (Evans et al., 2016), embodied, face to face interaction was 
considered crucial to ensure effective feedback provision; virtual relationships were less effective. Even more illuminating was discussion of where feedback was deliberately not provided or sought. In this regard, despite claims that they had facilitated the sharing of best practice, Public Health felt left out of the feedback loop: Susan (Public Health) explained:

[we don't get feedback] Not automatically no... there's no mechanism for it... feedback would largely go to the sports partnership because they've had that sort of odd role

Conversely, both Paul (Public Health) and Sam (CSP) suggested that the county network fora were designed for district level staff to give them, and one another, feedback about ERS effectiveness. Janet (district lead) felt that because of the way in which all ERS stakeholders, including third parties, were invited to network fora, her lack of familiarity with her audience limited her ability to provide valuable feedback on ERS effectiveness:

[the meetings are] rather an odd one - I have always wondered why [the meetings] do not set up as managers or instructors or contract managers. It is a mixture. I may be sat around the table with a sub-contractor or provider or someone who is directly responsible for how money is spent...It is a bugbear for me, particularly when I have not been at a meeting, when messages have gone to staff that really I could have done with knowing first - it is not the best vehicle, sometimes aimed in the wrong direction

Consequently, Janet actually opposed sharing information that she considered unsuitable for all who attended, fearing she was wasting their time. Because professionals from all levels of service provision were present at meetings, it seems the gradient between formal and informal relations was skewed toward informality (Wouters, 2014). Clear boundaries between job roles and competencies were blurred, and although meetings were conducted in a professional manner, lines of accountability (and therefore the character of power balances) remained opaque due to the lack of established bonds 
of association between all present. In short, meetings failed to produce a countywide 'We' group in ERS that could supersede district affiliation. In addition, several participants outlined how ERS impact also depended upon engagement levels from local PCHPs, over whom neither Public Health nor the CSP had any direct management, and who were not invited to quarterly fora. Christine (CSP) commented:

...it seems to be wild and woolly. It varies according to the provider and the relationship they have with their local GP practices

Exercise professionals, who demonstrated a strong sense of professional affiliation and 'we-group' identity, also emphasized the lack of communication between the county and district/local ERS levels, and between themselves and PCHPs. Aidan (Exercise Professional) explained:

There is a definite miscommunication...the negatives are definitely that there's no real communication between the council, the GPs and us as a three way network and by us I mean the people that are actually administering [the programme]...

Although characterised by a degree of 'blame gossip,' that is, negative labelling of 'they' groups (Elias \& Scotson, 1994), Exercise Professionals perceived a lack of strategic co-ordination in ERS, surmising that strategic managers at county level had little understanding of what was being delivered at ground-level. Conversely, strategic management were well aware that districts delivered different ERS service models. What was perceived at district level as 'weak leadership' instead reflected a deliberate strategy designed to enable district managers to set their own targets and to deliver locallytailored programmes. This was coupled with a perceived inability from strategic staff to 'police' each individual ERS. Sam (CSP) explained:

So I'd say there's still lots of disparity between the quality... coherence and certain competence of the instructors as well as the experience, the choice, the price... it's still very, 
very varied...the negatives are of course is that it is so varied and you can't, you can never control quality in this sort of environment... and you just never would unless you're going to police it. And if you're going to police it you'd have to spend an awful lot of money on the policing of it and then you lose your delivery money.

Hence, although all strategic managers recognised service inequality, most claimed they lacked the means and the budget to regulate programmes, and local delivery mechanisms remained unchallenged. As if to emphasize this point, Exercise Professionals also highlighted the importance of face-to-face, long-term and embodied partnership work, including good communication, supportive attitudes and consistency. This was considered particularly important between themselves and PCHPs, as Fran (Exercise Professional) expressed:

I suppose if you're working with other organisations... I think you all need to be singing off the same page, you all need to be, want to do it and you just need to gel together as a team which is hard when you're all working from different offices.

Again, the importance of diachronic processes of informalisation came to the fore (Wouters, 2014); that is, it apparently took time for stakeholders to learn to behave in an increasingly similar, cooperative manner towards ERS. This was not always possible, particularly for PCHPs, and no PCHP talked about partnership working in the same manner. Whilst some PCHPs were considered 'advocates' of ERS, others were considered less likely to refer patients. Exercise Professionals took this to indicate a 'lack of engagement' (Malcolm) or lack of commitment to the programme, particularly among GPs. This perception was supported in several ways. First, PCHPs' limited involvement after their referral of patients into ERS was cited. For example, Aidan (Exercise Professional) noted: 
I mean I was under the impression that GP referral schemes was in conference with GPs, this idea that, probably a stupid idea but I always assumed that there was that, GPs got together maybe with the council and discussed it but it doesn't seem to, you know I realise that was a naïve idea...

Second, several Exercise Professionals suggested that PCHPs did not take ERS seriously as a treatment option, and consequently felt disrespected as a professional group. Malcolm (Exercise Professional), who referred to himself as a 'Health professional' and PCHPs as 'medical professionals', highlighted issues of trust and professional boundaries:

Err I think what a lot of it has to do with the trust... maybe they don't trust who they're referring into... I think a lot of that comes because of the divide between us as in PCHPs and them as medical professionals and there being a lack of understanding of each other's speciality and there's a massive divide between the two.

Finally, it was a common opinion amongst Exercise Professionals that only a limited number of PCHPs really 'understood' or cared about ERS, or about the health benefits of PA/exercise. Incorrect completion of referral forms and failure to notify Exercise Professionals of health contraindications was cited as an example, and Fran (Exercise Professional) contrasted GPs' and physiotherapists' attitudes:

GPs, some of them are brilliant and you get loads from the same medical practice but others don't want anything to do with it and I don't know whether they don't believe in PA is of benefit or they just don't recognise the scheme... (but) we get a lot of physios - are very good obviously because they come from a PA background and so they're great for referring people in. 
Perhaps due to perceptions of disinterest amongst PCHPs, a number of Exercise Professionals confirmed they had not been asked for, and so did not offer, feedback on patient performance:

...in the year that I've been doing this they've never wanted feedback from, they've never requested it from me, as I said they kind of refer it and that's my contact with that GP gone (Aidan, Exercise Professional).

In contrast, PCHPs also made no comment upon the professional competence of Exercise Professionals. PCHPs also reported a desire to see feedback, and Tara (GP) described how feedback provided an insight into how motivated her patients were and how committed they were to behaviour change. As the provision of feedback from Exercise Professionals was not monitored, however, Exercise Professionals largely dictated how much was offered, to whom and how often. Therefore, at the local level and within ERS, Exercise Professionals were often arbiters of service delivery and feedback mechanisms. This group consistently demonstrated a strong sense of professional affiliation with a relatively cohesive and established 'we-group' identity, describing themselves as 'ultimately responsible' for ERS delivery. Their largely embodied bonds of association preceded those at county level, they were long-established, and the group often engaged in blame gossip and negative labelling of other 'they groups' including strategic staff at county level, and some PCHPs at the local level. Exercise Professionals did this by highlighting and generalising the mistakes of others, whilst suggesting that these 'They' groups did not really 'understand' ERS. Both PCHPs and strategic managers appeared unaware of this negative labelling, nor had a mechanism to respond directly to criticism (Lake, 2013). Notably, both groups had other significant priorities and responsibilities beyond ERS. Exercise Professionals evidently considered themselves the 'real' insiders to ERS. Moreover, the consequences of these perceptual fissures within service delivery pathways were considerable.

\section{Consequences}


At the time of this research, ERS provision was under serious review at the county level driven by limited resources, a need for demonstrable 'impact', and changes in health promotion policy. Primarily because of the lack of demonstrable 'impact' at the level of the population, ERS provision and funding were considered under threat; Paul (Public Health) feared that:

The goal was to try and reduce some disease levels and even our [the county's] obesity levels but the scale isn't big enough for that.

Interestingly in terms of ideological perspective, ERS 'impact' seemed to be defined at the population level only, in terms of the prevalence of 'disease' and 'obesity' on a countywide basis. Little emphasis was placed upon individual benefits, despite interviewees' initial assertions that ERS was a behaviour change programme. Despite failing to provide a clear definition of what constituted a sufficient magnitude of success, together with a lack of feedback data, strategic managers considered any successes to be 'small scale'. In part they blamed this on the local, rural context, but also felt that ERS was 'insufficient' at delivering changes to population health, particularly when compared with other programmes such as smoking cessation. Paul simply stated that in ERS, 'the numbers simply did not add up.' Which numbers, exactly, remained unclear.

At district level, the initial lack of funding for ERS made its small magnitude of impact inevitable, whilst a commitment to county-wide objectives, which were not always appropriate to the local context, was seen as a significant constraint:

...so now it's 'these are the conditions you'll accept, anything outside of that isn't within the funding or the remit', so there are certain things that we used to do that we are not allowed to do really, things like cardiac rehab for example phase IV intervention, it isn't something that Public Health want to fund (Janet, district lead).

Sam (CSP) also highlighted how: 
...we just don't have the funds or the reach or actually the capacity to deal with those people even if they were all referred.

The consequences quickly became clear, and blame for programme failure was swift to follow, albeit without consistent direction. Christine (CSP) emphasized how the overall 'failure' of ERS provision was due to poor local service quality:

I can't see that...the county council are going to support it for the future whereas if it had been absolutely fantastic they would have no reason not to support it

Conversely, Sam (also CSP) believed that the blame resided with those in national strategic positions:

If NICE ever decided to have a decent opinion about it, it would be quite worthwhile but they've been ambivalent and maintain their ambivalence and I can't quite figure out why

What was clear at the time of research, however, was that many were fearful for the future, and Janet (district lead) expressed how ERS had become construed as an unaffordable 'luxury':

For the county I think it is bleak because it is one of those things that has become a luxury, as have many lifestyle programmes, a luxury most local authorities cannot afford in the main.

In 2016, during the period of study, central funding for ERS provision was discontinued. From a figurational perspective, such outcomes are neither planned nor foreseen. Instead, they result from the interdependent actions of all within the group, many of which are based upon inadequate knowledge of the full extent of the figuration within which individuals are situated, and their ability to influence it or are constrained by it (Mennell, 1994). The result of these actions was a withdrawal of central funding, and a return to ERS delivery mechanisms that had previously existed at the local level. Shortly after data collection was completed, members of the 'Public Health' organisation announced the decommissioning of 'non-essential' services. ERS, it seems, was considered thus. Districts were offered the opportunity to continue to deliver ERS under their own commercial model. 
Some districts took the decision to continue, with their larger schemes remaining but at a cost to the patient, whilst other ERS ceased. Exercise, it appeared, was deemed too costly a medicine to fund from the public purse.

\section{Summary \& Conclusions}

Here, we have presented key themes based on interview data from 17 ERS stakeholders in one case study county, spanning strategic managers, Exercise Professionals and PCHPs. Problems highlighted by participants included a lack of clearly defined goals for ERS, and a tendency toward lifestyle drift in which ERS was presented as a solution to population-level health inequalities via deployment of an individual behaviour-change model. From our figurational-sociological perspective, interactions along interdependency chains between stakeholders at several levels of service provision resulted in contestation around how ERS services should be delivered, by whom, and what would constitute an appropriate level of 'impact'. ERS roles and responsibilities were similarly contested. Often this was via the selective use and distribution of feedback, funding allocations, and via stigmatisation and blame gossip, through which multiple, and various 'We' groups asserted their ability to control service delivery and challenged the competencies of others. This made attempts to standardise ERS across the county challenging for strategic managers, whose attempts at governance by network were constrained by the existing, district level bonds of association between Exercise Professionals and a small number of PCHPs. Even within local networks, power-balances were contested. Exercise Professionals in particular seemed to emphasize their 'insider' knowledge of what ERS 'actually' was at the point of delivery, whilst several groups simultaneously claimed that other 'They' groups of professionals simply did not understand ERS, often to the point of identifying perceived ineptitude and group-level failings.

The qualitative findings revealed the complexities, contested nature, and unintended elements of ERS, for policies and programmes, which are often considered to be standardised, are rarely uniform or 
delivered in intended ways. Even intra a particular organisation, interpretations of programme aims and objectives can widely differ. Nor are exercise/PA and health programmes merely about outcomes, impacts, or engendering positive experiences amongst 'service end users'. Programmes are also contoured by relationships between service providers and stakeholders. Moreover, the interpretation of service providers is not something to be controlled in health and exercise/PA programmes, nor are policies, programmes or the institutions that deliver programmes 'things' that think or act by themselves. Institutions, as figurations, are constituted by the people within and around them. Thus, from a figurational perspective, institutions contain hierarchies, established and outsider groups, and are comprised of tensile, contested and changing bonds of association in interdependency chains that often extend beyond the control or awareness of individuals. Nevertheless, it is according to these interdependency chains that the actions of all intertwine to create unintended programmes impacts and outcomes (Elias \& Schröter, 1991). This is the essence of programme emergence (Pawson, 2013). Hence, multidirectional interdependency chains of relationships, both embodied and virtual, are shaped by multiple, tensile balances that change through time and space according to resources (both human and physical), creating considerable complexity in terms of how programmes are delivered, by whom, when and where. Programmes are constituted by people, and people produce, enact, interpret and contest policies and programmes in complex ways.

Hence, health and exercise programmes do not work per se; it is the interpretations of their subjects - or I, We and They groups, both end users and service providers - that produce results (Pawson, 2013). It has been argued that the greater number of people involved in a programme and the greater number of hands a service passes through, the greater the space for (re)interpretation, the more the impact of a programme tends toward zero (Rossi, 1987). It could be added that in larger programmes there is also a greater potential for the intended actions of the few to intertwine with the actions of many others to create unintended consequences across a programme. What is more, health and 
exercise programme impact cannot be isolated from the world; they exist in the world (Pawson, 2013). Resources, competencies, levels of engagement and bonds of association have a diachronic (that is, processual) nature as well as synchronic character which means that some programmes work for some people in some locations, others do not. Hence the simple inference of causation between individual behaviour change initiated by exercise as medicine and population level health change is, at best, questionable. Small wonder then that attempts to standardise ERS delivery mechanisms across our case-study county, in order to enact population-level health changes were rendered problematic. Given the heterogeneous early development of ERS, with its reliance upon local, embodied and longestablished bonds of association between Exercise and PCHPs, perhaps resistance at the local level was only to be expected.

Whilst there are research limitations in terms of the size of the study and its specific geographical location, the study nevertheless has implications for how exercise is considered as 'medicine.' In this case, the prescribed 'medicine' is not a drug, nor does it relate to a targeted course of treatment over a given time period that aims to mitigate a specific set of symptoms. Sedentariness is not a disease, it is a lifestyle behaviour. Hence, exercise 'treatment' is not limited to 10 to 16 weeks; engagement in exercise is construed as being ideally maintained across a life course. In this respect, the lack of reference from participants to the process of weaning participants off ERS and ensuring they adopted long-term active lifestyles is notable. Indeed, exercise is experienced and interpreted by participants in multifaceted and complex ways that change over time. Human behaviour is complex, hard to predict, and is subject to wider social inequalities that can influence whether participants can 'choose' to adhere to their prescription at all. What's more, exercise as medicine is also interpreted and delivered according to the behaviours, beliefs and experiences of service providers. Many programmes focus upon 'getting the message across' and 'getting the packaging right' to promote the exercise 'message' in order to alter the behaviour of inactive individuals one by one, (Kelly \& Barker, 
2016). They may fail, however, to recognise that the actions and interpretations of programme stakeholders can fundamentally alter message, packaging, delivery mechanisms and programme receipt. Indeed, these can potentially influence the very existence of a programme. Hence, by focusing purely upon the physiological, psychological or even socio-cultural impact of an exercise 'prescription' on service end users or target populations, we risk failing to understand how the perceptions, norms and beliefs of those administering a programme of exercise-as-medicine can fundamentally alter its nature from case to case, context to context. As in any other figuration, therefore, the actions of individuals can have unintended consequences across figurations; exercise as medicine is anything but predictable. This complexity, of understanding what works, for whom and in what circumstances, can only be partially explained via end-user experience.

\section{Acknowledgements}

The authors would like to thank interview participants, without whose time and input the research could not have been completed.

\section{References}

Baur, N., \& Ernst, S. (2011). Towards a process-oriented methodology: modern social science research methods and Norbert Elias's figurational sociology. The sociological review, 59(s1), 117-139.

Beck, F. E., Gillison, F. B., Koseva, M. D., Standage, M., Brodrick, J. L., Graham, C., \& Young, H. (2016). The systematic identification of content and delivery style of an exercise intervention. Psychology \& Health, 31(5), 605-621.

BHF. (2010). Exercise Referral Toolkit. Loughborough, UK: 
Bradley, E. H., Curry, L. A., \& Devers, K. J. (2007). Qualitative data analysis for health services research: developing taxonomy, themes, and theory. Health services research, 42(4), 17581772.

Bryman, A., \& Teevan, J. J. (2004). Social research methods (Vol. 2). Oxford: Oxford university press

Bull, F. C., \& Bauman, A. E. (2011). Physical inactivity: the "Cinderella" risk factor for noncommunicable disease prevention. Journal of health communication, 16(sup2), 13-26.

Carey, G., Malbon, E., Crammond, B., Pescud, M., \& Baker, P. (2016). Can the sociology of social problems help us to understand and manage 'lifestyle drift'? Health Promotion International, $1,1-7$.

Centre for Disease Control. (2011). School health guidelines to promote healthy eating and physical activity. MMWR. Recommendations and reports: Morbidity and mortality weekly report. Recommendations and reports, 60(RR-5), 1.

Clarke, V., \& Braun, V. (2014). Thematic analysis Encyclopedia of critical psychology. London: Springer.

Crone, D., \& James, D. (2016). Evidence-Based Practice in Physical Activity Promotion. In Scott, A. and Gidlow, C (eds) Clinical Exercise Science. London: Routledge

Department of Health, (2011). Start active, stay active: report on physical activity in the UK. London

Dugdill, L., Graham, R. C., \& McNair, F. (2005). Exercise referral: the public health panacea for physical activity promotion? A critical perspective of exercise referral schemes; their development and evaluation. Ergonomics, 48(11-14), 1390-1410.

Dunning, E. (1999). Sport matters: Sociological studies of sport, violence, and civilization. London: Taylor \& Francis. 
Durstine, J. L., Gordon, B., Wang, Z., \& Luo, X. (2013). Chronic disease and the link to physical activity. Journal of Sport and Health Science, 2(1), 3-11.

Elias, N. (1982). The civilizing process, 2 vols. New York: Pantheon.

Elias, N., \& Dunning, E. (1986). Quest for excitement: sport and leisure in the civilizing process. Oxford, New York: Basil Blackwell

Elias, N., \& Schröter, M. (1991). The society of individuals: London: Continuum International Publishing Group.

Elias, N., Schröter, M., \& Jephcott, E. (1987). Involvement and detachment: Basil Blackwell: Oxford.

Elias, N., \& Scotson, J. L. (1994). The established and the outsiders: A sociological enquiry into community problems (Vol. 32). London: Sage Publications Ltd.

Evans, A. B., Carter, A., Middleton, G., \& Bishop, D. C. (2016). Personal goals, group performance and 'social' networks: participants' negotiation of virtual and embodied relationships in the 'Workplace Challenge' physical activity programme. Qualitative research in sport, exercise and health, 8(2), 301-318.

Evans, A. B., \& Crust, L. (2015). 'Some of these people aren't as fit as us ...': experiencing the ageing, physically active body in cardiac rehabilitation. Qualitative research in sport, exercise and health, 7(1), 13-36.

Evans, A. B., \& Sleap, M. (2012). "You feel like people are looking at you and laughing": Older adults' perceptions of aquatic physical activity. Journal of aging studies, 23(4), 515 - 526.

Moore, G., Raisanen, L., Moore, L., Ud Din, N., \& Murphy, S. (2013). Mixed-method process evaluation of the welsh national exercise referral scheme. Health Education, 113(6), 476-501.

Fitzsimons, C., Baker, G., Wright, A., Nimmo, M., Ward Thompson, C., Lowry, R., . . Mutrie, N. (2008). The 'Walking for Wellbeing in the West' randomised controlled trial of a pedometer- 
based walking programme in combination with physical activity consultation with 12 month follow-up: rationale and study design. BMC public health, 8(1), 259.

Gidlow, C., Johnston, L. H., Crone, D., \& James, D. V. (2008). State of the art reviews: methods of evaluation: issues and implications for physical activity referral schemes. American Journal of Lifestyle Medicine, 2(1), 46-50.

Goudsblom, J. (1977). Sociology in the Balance: A Critical Essay. Oxford: Blackwell.

Graham, R., Dugdill, L., \& Cable, N. (2005). Health professionals' perspectives in exercise referral: implications for the referral process. Ergonomics, 48(11-14), 1411-1422.

Grix, J., \& Phillpots, L. (2011). Revisiting the 'Governance Narrative'A Asymmetrical Network Governance'and the Deviant Case of the Sports Policy Sector. Public Policy and Administration, 26(1), 3-19.

Hardcastle, S., \& Taylor, A. H. (2001). Looking for more than weight loss and fitness gain: Psychosocial dimensions among older women in a primary-care exercise-referral program. Journal of Aging and Physical Activity, 9(3), 313-328.

Harrison, R. A., Roberts, C., \& Elton, P. J. (2005). Does primary care referral to an exercise programme increase physical activity one year later? A randomized controlled trial. Journal of Public Health, 27(1), 25-32.

Hillsdon, M. (1998). Promoting physical activity: issues in primary health care. International journal of obesity and related metabolic disorders: journal of the International Association for the Study of Obesity, 22, S52-54.

Hillsdon, M., Thorogood, M., White, I., \& Foster, C. (2002). Advising people to take more exercise is ineffective: a randomized controlled trial of physical activity promotion in primary care. International Journal of Epidemiology, 31(4), 808-815. 
Hippisley-Cox, J., Fenty, J., \& Heaps, M. (2007). Trends in consultation rates in general practice 1995 to 2006: analysis of the QRESEARCH database. London: QRESEARCH and The Information Centre for health and social care.

Jarvie, G., \& Maguire, J. A. (1994). Sport and leisure in social thought. London: Taylor \& Francis.

Kahn, E. B., Ramsey, L. T., Brownson, R. C., Heath, G. W., Howze, E. H., Powell, K. E., . . Briss, P. A. (2002). The effectiveness of interventions to increase physical activity - A systematic review. American Journal of Preventive Medicine, 22(4), 73-108.

Kelly, M. P., \& Barker, M. (2016). Why is changing health-related behaviour so difficult? Public Health, 136, 109-116.

Lake, R. J. (2013). 'They treat me like I'm scum': Social exclusion and established-outsider relations in a British tennis club. International Review for the Sociology of Sport, 48(1), 112-128.

Lee, I.-M., Shiroma, E. J., Lobelo, F., Puska, P., Blair, S. N., Katzmarzyk, P. T., \& Group, L. P. A. S. W. (2012). Effect of physical inactivity on major non-communicable diseases worldwide: an analysis of burden of disease and life expectancy. The Lancet, 380(9838), 219-229.

Maguire, J. A. (2005). Power and global sport: zones of prestige, emulation and resistance: London: Psychology Press.

Malcolm, D. (2016). Sport, Medicine and Health: The medicalization of sport? London: Routledge.

Mansfield, L. (2007). Involved-detachment: a balance of passion and reason in feminisms and genderrelated research in sport, tourism and sports tourism. Journal of Sport \& Tourism, 12(2), 115141.

Mennell, S. (1994). The formation of we-images: a process theory. In Calhoun, C. (ed) Social theory and the politics of identity. Oxford: Wiley-Blackwell

Morgan, F., Battersby, A., Weightman, A. L., Searchfield, L., Turley, R., Morgan, H., ... Ellis, S. (2016). Adherence to exercise referral schemes by participants-what do providers and 
commissioners need to know? A systematic review of barriers and facilitators. BMC public health, 16(1), 227.

Morgan, O. (2005). Approaches to increase physical activity: reviewing the evidence for exercisereferral schemes. Public Health, 119(5), 361-370.

Mutrie, N., \& Woods, C. (2003). How can we get people to be more active? A problem waiting to be solved. In J. McKenna \& C. Riddoch (Eds.), Perpsectives on health and exercise (pp. 131152). Basingstoke: Palgrave McMillan.

National Health Service. (2001). Exercise referral systems: A National quality assurance framework: Crown Copyright, London.

National Health Service Scotland (2006). Commentary on NICE Public Health Intervention Guidance: Four commonly used methods to increase physical activity: brief interventions in primary care, exercise referral schemes, pedometers and community-based exercise programmes for walking and cycling. Edinburgh

National Institute for Clinical Excellence. (2006). A rapid review of the effectiveness of pedometer interventions to promote physical activity in adults. London.

National Institute for Clinical Excellence. (2013). Physical activity: brief advice for adults in primary care. London:

National Institute for Clinical Excellence. (2014). Physical activity: exercise referral schemes. London:

Oliver, E., Hanson, C., Lindsey, I., \& Dodd-Reynolds, C. (2016). Exercise on referral: evidence and complexity at the nexus of public health and sport policy. International Journal of Sport Policy and Politics, 8(4), 731-736. 
Pavey, T., Taylor, A., Fox, K., Hillsdon, M., Anokye, N., Campbell, J., . . Mutrie, N. (2011). Effect of exercise referral schemes in primary care on physical activity and improving health outcomes: systematic review and meta-analysis. Bmj, 343, d6462.

Pawson, R. (2013). The science of evaluation: a realist manifesto. London: Sage.

Popay, J., Whitehead, M., \& Hunter, D. J. (2010). Injustice is killing people on a large scale—but what is to be done about it? Journal of Public Health, 32(2), 148-149.

Rossi, P. (1987). The iron law of evaluation and other metallic rules. Research in social problems and public policy, 4: 3-20.

Shilling, C. (2003). The body and social theory. London: Sage Publications Ltd.

Smith, B., \& Sparkes, A. C. (2016). Qualitative interviewing in the sport and exercise sciences. In Smith, B. and Sparkes, A. (eds). Routledge handbook of qualitative research in sport and exercise. London: Routledge

Sowden, S., \& Raine, R. (2008). Running along parallel lines: how political reality impedes the evaluation of public health interventions. A case study of exercise referral schemes in England. Journal of Epidemiology and Community Health, 62(9), 835-841.

Sparkes, A. C., \& Smith, B. (2013). Qualitative research methods in sport, exercise and health: From process to product. Abingdon, Oxon: Routledge.

Thomas, D. R. (2006). A general inductive approach for analyzing qualitative evaluation data. American journal of evaluation, 27(2), 237-246.

Thorp, A. A., Owen, N., Neuhaus, M., \& Dunstan, D. W. (2011). Sedentary behaviors and subsequent health outcomes in adults: a systematic review of longitudinal studies, 1996-2011. American Journal of Preventive Medicine, 41(2), 207-215.

Tulle, E., Dorrer, N. . (2012). Back from the brink: Ageing, exercise and health in a small gym. Ageing and Society, 32(7), 1106-1127. 
Ward, M. (2014). Experiences in physical activity promotion in health care settings for primary prevention in the UK. Médecine et traumatologie du sport Rivista svizzera di Medicina e traumatologia dello sport, 62(2), 26-28.

Weiler, R., Murray, A., \& Joy, E. (2013). Do all health care professionals have a responsibility to prescribe and promote regular physical activity: or let us carry on doing nothing. Current sports medicine reports, 12(4), 272-275.

Wheatley, E. E. (2005a). Discipline and Resistance: Order and Disorder in a Cardiac Rehabilitation Clinic. Qualitative Health Research, 15(4), 438-459.

Wheatley, E. E. (2005b). Disciplining bodies at risk: Cardiac Rehabilitation and the Medicalization of Fitness. Journal of Sport \& Social Issues, 29(2), 198-221.

Williams, N. H., Hendry, M., France, B., Lewis, R., \& Wilkinson, C. (2007). Effectiveness of exercise-referral schemes to promote physical activity in adults: systematic review. The British Journal of General Practice, 57(545), 979.

World Health Organisation, (2013). World Health Statistics 2013. Geneva, Switzerland

Wormald, H., \& Ingle, L. (2004). GP exercise referral schemes: Improving the patient's experience. Health Education Journal, 63(4), 362-373.

Wouters, C. (2014). Universally applicable criteria for doing figurational process sociology: Seven balances, one triad. Human Figurations, 3(1). 